\title{
CAPSULE COMMENTARIES Capsule Commentary on Guerrasio and Aagaard, Methods and Outcomes for the Remediation of Clinical Reasoning
}

\author{
Gurpreet Dhaliwal, MD
}

Department of Medicine, University of California San Francisco and Medical Service, San Francisco Veterans Affairs Medical Center, San Francisco, CA, USA.

J Gen Intern Med 29(12): 1687

DOI: $10.1007 /$ s11606-014-2971-1

(c) Society of General Internal Medicine 2014

"R ead more, see more" is one of the most common constructive comments for students and residents who struggle with clinical reasoning. It's a well-intentioned prescription, but it doesn't work. In this issue, Guerrasio and Aagaard describe an approach that does. ${ }^{1}$

They present a single-center study of 53 students, residents, and fellows with clinical reasoning deficits who underwent a standardized remediation program. Ninety-one percent of the trainees achieved competence and graduated. Referrals came from clerkship and program directors who also judged adequacy of remediation based on assessment tools and evaluations by supervising clinicians. Some readers may prefer more standardized entry and exit criteria, but this approach is pragmatic and ecologically valid.

Medical education programs seeking to achieve similar success in remediating clinical reasoning should note the details of this approach, but should pay even closer attention to these key lessons:

(1) Practice, not theory. The path to acceptable real-world performance is forged by repeatedly grappling with authentic problems, not by a month of reading. In this study, trainees engaged in deliberate practice by methodically completing dozens of case exercises under faculty guidance.

(2) It takes a village. Kalet and Zabar outline 17 competencies that a clinician-educator conducting remediation should possess. $^{2}$ In this program, those skills and responsibilities are shared among a remediation team.

(3) It takes time. Establishing and rebuilding neural networks is painstaking work. The average faculty time per trainee was 30 hours, but it sometimes took 100 hours. Remediation of clinical reasoning requires more time than other skills. ${ }^{3}$

(4) Beyond clinical reasoning. Less than a quarter of the trainees had deficits in clinical reasoning alone. Attention must also to be paid to clinical and organizational skills, mental health issues, and psychosocial stressors.

Most teachers recognize inadequate reasoning when they see it, but few have a structured approach to remediating it. ${ }^{4}$ They want to help, but wonder, "What does it take?" This study provides an honest answer. It requires a resourceintensive commitment from the faculty and the institution aimed at reconstructing and reorganizing knowledge through repeated cycles of practice, reflection, and feedback. It requires much more than "read more, see more."

Conflict of Interest: The author has no conflict of interest with regard to the material in this article.

Corresponding Author: Gurpreet Dhaliwal, MD; Department of Medicine, University of California San Francisco and Medical Service, San Francisco Veterans Affairs Medical Center, San Francisco, CA, USA (e-mail: gurpreet.dhaliwal@ucsf.edu).

\section{REFERENCES}

1. Guerrasio J, Aagaard EM. Methods and Outcomes for the Remediation of Clinical Reasoning. J Gen Intern Med. 2014; (Article SPI \#2955)

2. Kalet A, Zabar S. Preparing to Conduct Remediation. In Kalet A, Chou C (eds). Remediation in Medical Education: A Mid-Course Correction. New York: Springer; 2014:311.

3. Guerrasio J, Garrity MJ, Aagaard EM. Learner deficits and academic outcomes of medical students, residents, fellows, and attending physicians referred to a remediation program, 2006-2012. Acad Med. 2014;89(2):352-8.

4. Audétat MC, Dory V, Nendaz M, Vanpee D, Pestiaux D, Junod Perron N, Charlin B. What is so difficult about managing clinical reasoning difficulties? Med Educ. 2012;46(2):216-27. 